\title{
Tandem Mass Spectrometry and Glycoproteins
}

\author{
Pavlina Dolashka \\ Institute of Organic Chemistry with Centre of Phytochemistry, \\ Bulgarian Academy of Sciences, Sofia, \\ Bulgaria
}

\section{Introduction}

Glycoproteins and glycopeptides are organic compounds that are composed of both polypeptide and carbohydrate chains bonded together. For many years glycoproteins and glycopeptides have been a subject of interest; however, recently they have aroused the interest of biochemists and biologists from a wide range of fields. This increased interest is partly due to the fact that glycoproteins were discovered to be abundant in living organisms and glycoproteins appear in nearly every biological process studied. Glycoproteins help many systems within the human body to function properly and optimally, and deficiencies can be responsible for a whole spectrum of diseases, conditions and ailments. Examples of glycoproteins include antibodies that interact directly with antigens. Major histocompatibility complex molecules that interact with the T-cells as part of an adaptive immune response and hemocyanins (Hcs) fudge molecules that transport oxygen in mollusks and arthropods.

Detailed knowledge of protein glycosylation at the proteome level is becoming an important aspect of post-genomic research. Moreover, glycobiology seeks to identify the molecular structure of glycopeptides and to further explore the function of such peptides in relation to other cells and molecules in the body. By determining how glycopeptides are structured and in order to better understand how they work, researchers working in the field of glycobiology may be able to produce treatments and therapies that improve health and may prolong life. Therefore, the development and application of different analysis techniques will increase the knowledge of their structure and function. A number of reviews have been published in the last few years on analytical methods, including chromatography, electrophoresis and MS, for the characterization of glycans and glycoproteins (Zaia, 2004; Morelle et al. 2005; Dell and Morris 2010), and on general MS-based proteome and peptide analysis methods (Medzihradszky, 2005; Domon et al. 2006; Froehlich et al. 2011).

Mass spectrometric (MS) techniques play a key role in glycoprotein and glycan analysis, to study protein glycosylation at the glycopeptide level. Therefore, MS is becoming an increasingly important aspect in proteomics. Current informatics tools are designed for large, high-throughput mass-spectrometry datasets.

One of the analytical instruments used in laboratories a tandem mass spectrometer. This instrument can analyze numerous compounds, such as those in body fluids and in the environment. Enrichment and separation techniques for glycoprotein and glycopeptide from complex (glyco-) protein mixtures and digests are summarized below. In addition to detection by mass spectrometry, the microarray platform has also become an essential tool 
to characterize glycan structures and to study glycosylation-related biological interactions; here one uses probes as a means to interrogate the spotted or captured glycosylated molecules on the arrays.

\section{Glycoproteomics}

Almost all secreted and membrane-associated proteins are glycosylated through posttranslational modification. Protein glycosylation is one of the most important posttranslational modifications in eukaryotes, but remains poorly investigated. N-linked glycans, with a common monosaccharide core and specific attachment motif, appear to be amenable to analysis, but significant difficulties remain.

The key structural issues of glycoproteomics are protein identification, glycosylation site determination, and glycan profiling at individual attachment sites (Tadjiri et al. 2005; Harvey, 2006). The structure of glycoproteins and glycopeptides is composed of a peptide chain with one or more carbohydrate moieties which constitute from less than $1 \%$ to more than $80 \%$ of the total protein mass. Glycoproteins usually exist as complex mixtures of glycosylated variants (glycoforms). Glycosylation occurs in the endoplasmic reticulum (ER) and Golgi compartments of the cell and involves a complex series of reactions catalyzed by membrane-bound glycosyltransferases and glycosidases.

Based on the saccharide chains, referred to as glycans, two main classes of glycoprotein structures are known: N-glycosylation, in which the oligosaccharide is attached to an asparagine residue, and O-glycosylation, in which the oligosaccharide is attached to a serine or threonine residue. The O-linked glycans consist of $\mathrm{N}$-acetylgalactosamine attached to the O-terminus of a threonine (Thr) or serine (Ser) residue (Fig. 1). The most common type of Olinked glycans contain an initial GalNAc residue (or Tn epitope); they are commonly referred to as mucin-type glycans. Other O-linked glycans include glucosamine, xylose, galactose, fucose, or mannose as the initial sugar bound to the Ser/Thr residues.

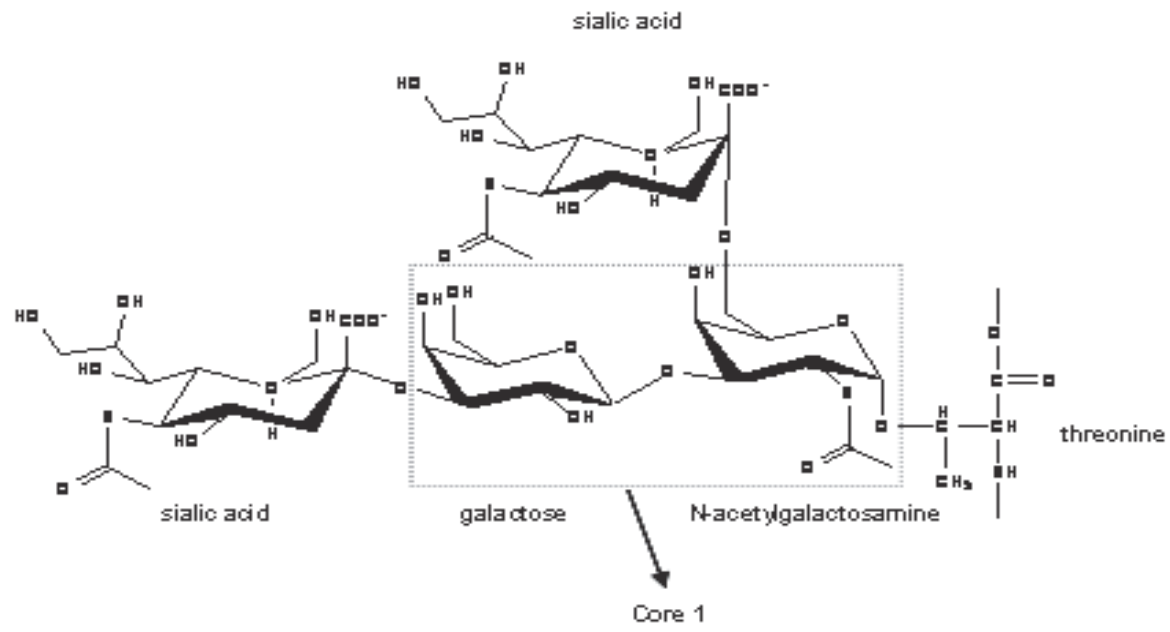

Fig. 1. O-linked glycan contain terminal N- acetyl neuraminic acid attached to a threonine residue. 
The other class of glycoproteins are the N-linked glycans. These molecules consist of an Nacetylglucosamine bond to the amide nitrogen of an asparagine molecule, where $X$ can be any amino acid (-X-Asn-X-Thr-) (Fig.2A,B).

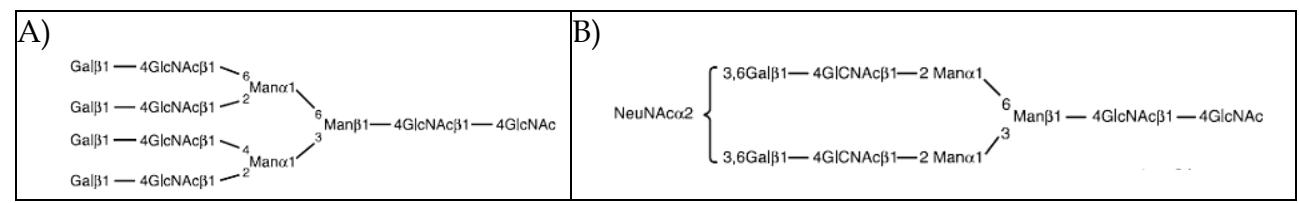

Fig. 2. A) Structures of a glycan at $\mathrm{m} / \mathrm{z} 2393[\mathrm{M}+\mathrm{Na}]+$ determined in matrix 2,5-

dihydroxybenzoic acid (DHB) B). Structure of an acidic glycan at m/z 1932 [M-H]determined in matrix 6-aza-2-thiothymine and 2,4,6-trihydroxyacetophenone (THAP).

Because carbohydrates and proteins by themselves serve in a vast number of biological functions, such as structure, enzymes, protection, carriers, immunological, defense, inhibitors, reproduction, etc. several techniques and analytical methods including chromatography, electrophoresis and MS-based proteome and peptide analysis are applied for the characterization of glycans and glycoproteins (Wada 2008; Sandra et al. 2004, 2007).

Another of these methods is nuclear magnetic resonance spectroscopy (NMR). The method is used to obtain information about the structure and dynamics of proteins and glycans. However, mass spectrometry has several advantages over NMR with respect to analysis of H/D exchange reactions: much less material is needed, the concentration of protein or glycan can be very low (as low as $0.1 \mathrm{uM}$ ), the size limit is much greater, and data can usually be collected and interpreted much more quickly.

A very important advantage is that mass spectrometry offers different techniques and approaches. Tandem mass spectrometry of the glycopeptides, isolated from tryptic digests of glycoproteins can be performed in a rapid and sensitive manner. Electrospray ionization (ESI) or matrix-assisted laser desorption/ionization (MALDI) mass spectrometry can be used. In the case of MALDI, profiling of oligosaccharides is achieved more appropriately by the linear time-of-flight (TOF) mode than in the reflection mode. Robust and reliable identification of proteins and the determination of the attachment sites often requires multiple-stage tandem mass spectrometry (Wada 2008).

Combining gel and capillary electrophoresis, nano-LC and mass spectrometry, the elucidation of post-translational modifications of Trichoderma reesei cellobiohydrolase I (Sandra et al. 2004 a) of hemocyanin isolated from marine snails Rapana venosa (Sandra et al.2007, Dolashka-Angelova et al. 2004) and of superoxide dismutase (Cu/Zn-SOD) from $K$. marxianus NBIMCC 1984 yeast (Dolashka et al. 2010) were analysed.

The strategy used for the characterisation of RvH1 N-glycosylation combines two main approaches (Fig. 3), where the intact $\mathrm{RvH}_{1}$ was subjected to PNGase F digestion and/or tryptic digestion. The first approach includes reduction and alkylation of RvH1 followed by PNGase F digestion of oligosaccharires from the protein. The $\mathrm{N}$-glycans were analysed by MALDI-TOF and CE-MS and followed by 8-aminopyrene-1,3,6-trisulphonate (APTS) and 3aminopyrazole (3-AP) labelling. Derivatisation of the oligosaccharides with APTS permits high-resolution $\mathrm{CE}$, allows the simultaneous detection of uncharged and charged glycans and provides easily interpretable spectra. 


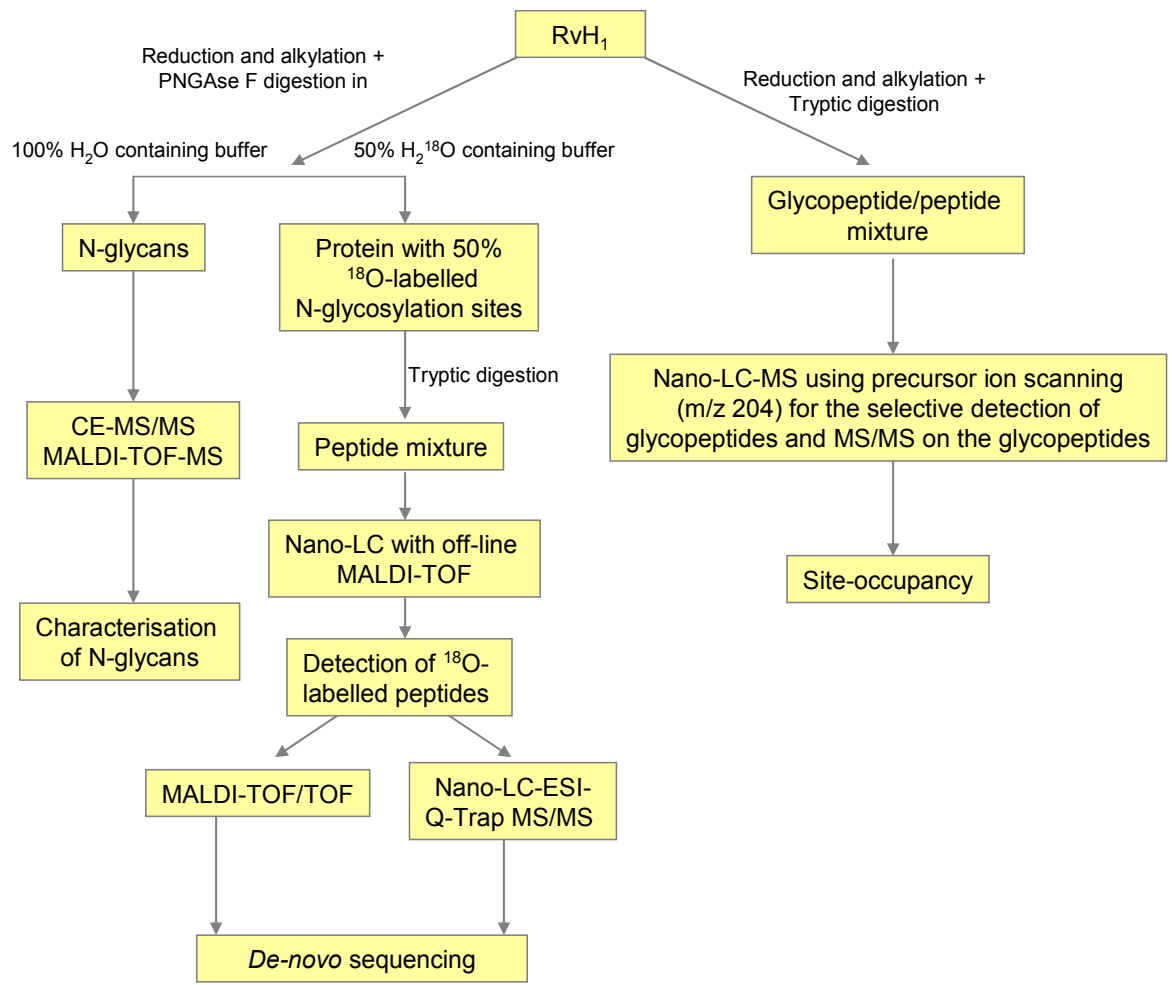

Fig. 3. Strategy used for the characterisation of the oligosaccharide structure of RvH1.

The second approach includs reduction and alkylation followed by tryptic digestion of the glycoprotein. The N-glycopeptides were analysed by MALDI-TOF and nano-LC-MS or nano-LC-ESI- techniques. Since the protein sequence of $\mathrm{RvH}_{1}$ is currently unknown, de novo MS sequencing had to be performed on the glycopeptides. Proteomic techniques, such as HPLC coupled to tandem mass spectrometry (LC-MS/MS), have proven to be useful for the identification of specific glycosylation sites of glycoproteins (glycoproteomics).

However, glycosylation sites of glycopeptides produced by trypsinization of complex glycoprotein mixtures are particularly difficult to identify because glycopeptides are usually present in relatively low abundance $(2 \%$ to $5 \%)$ in peptide mixtures compared to the nonglycosylated peptides, and because the sugar fragments in the MS spectrum often dominate the peptide fragments due to glycosidic bonds being more labile than peptide bonds. Some approaches have been developed to overcome this problem, mainly based on multistage MS (Bateman et al. 1998, Demelbauer et al. 2004), electron capture dissociation (ECD) (Håkansson et al. 2001, 2003) or electron transfer dissociation (ETD) (Hogan et al. 2005).

\section{Tandem mass spectrometry technique for glycoprotein and glycopeptide analysis}

An important application using tandem mass spectrometry is in protein identification. The simplest form of the technique combines two mass spectrometers. One of these instruments 
is a Matrix-Assisted-Laser-Desorption/Ionization-Time-of-Flight-Mass-Spectrometer (MALDI-TOF/TOF-MS), where the first mass spectrometer is used to select a single (precursor) mass from the MS spectrum of a mixture of the precursor. After collisional activation (CA) or collision-induced dissociation (CID), the second mass spectrometer is used to separate the fragments ions according to their masses. The resulting "MS/MS" spectrum consists only of production ions from the selected precursor (Fig.4).
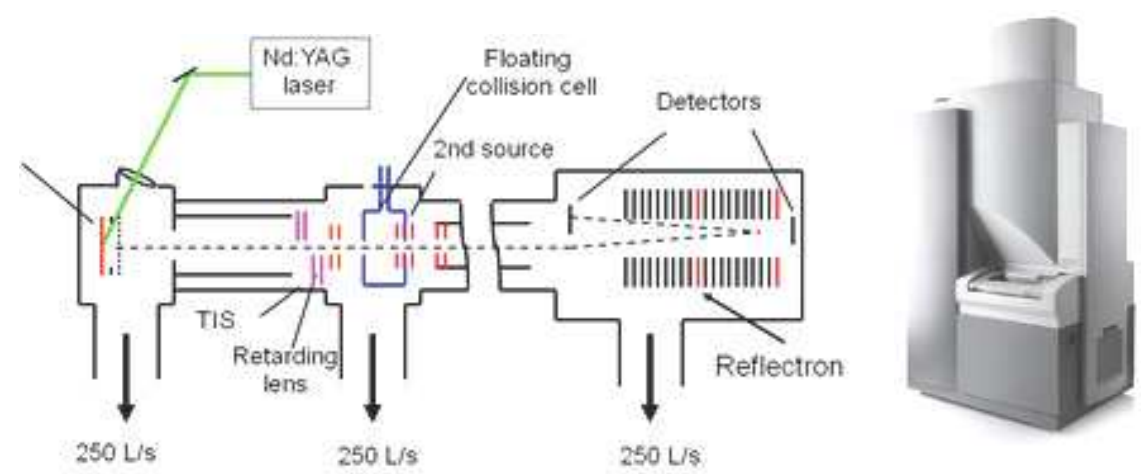

Fig. 4. Matrix-Assisted-Laser-Desorption/Ionization-Time-Of-Flight-Mass-Spectrometer (MALDI-TOF/TOF-MS).

There are various methods for fragmenting molecules by tandem MS, including:

- collision- induced dissociation (CID),

- electron capture dissociation (ECD),

- electron transfer dissociation (ETD),

- infrared multiphoton dissociation (IRMPD),

- blackbody infrared radiative dissociation (BIRD),

- electron-detachment dissociation (EDD) and

- $\quad$ surface-induced dissociation (SID).

Tandem mass spectrometry of glycopeptides is known as one of the most important tools in structural glycoproteomics. Various tandem MS (MS/MS) techniques for the analysis of glycopeptides as MALDI, MALDI-TOF/TOF-MS or MALDI-quadrupole-TOF were applied and compared with respect to the information they provide on peptide sequence, glycan attachment site and glycan structure. Glycopeptide ionization was performed mainly by CID or ETD.

\subsection{Collision-induced dissociation}

Early experiments with ESI and collision-induced dissociation (CID) on a triple-quadrupole mass spectrometer have already established several of the key features of CID of glycopeptides (Huddleston et al. 1993; Medzihradszky et. al. 1996). On the basis of this pioneering work, ESI with CID of glycopeptides has become a key tool in glycoproteomics. The potential of nano-ESI with a quadrupole-TOF mass analyzer for the characterization of $\mathrm{N}$ - and O-glycopeptides has been shown to be a sensitive tool that provides information on glycan structure, glycan attachment site, and peptide sequence. This method has been successfully applied to the characterization of O-glycosylated peptides carrying the Tn- 
antigen (GalNAc $\beta 1-$ ), the T-antigen disaccharide, or other slightly more elongated O-glycans based on $\beta$-linked GalNAc, attached to serine or threonine residues (Chalabi et al. 2006). Another type of glycosylations, analyzed by nano-ESI-quadrupole-TOF are O-fucosylation (Macek et al. 2001), O-linked N-acetylglucosamine (Vosseller et al. 2006), as well as Cmannosylation (Gonzales de Peredo et al. 2002). The C-linked mannose appeared to be very stable in CID, in contrast to O-glycans and N-glycans.

\subsection{Electron-transfer dissociation (ETD)}

Similar to the peptide structural information obtained from CD, electron-transfer dissociation has recently emerged as an MS/MS technique complementary to CID and RMPD. Peptide fragmentation is generated through gas-phase electron-transfer eactions from singly charged anions to multiply charged protonated peptides. Singly charged anions are used as vehicle for the electron delivery to the multiply protonated peptides.

Analogous to ECD, dissociation from electron transfer results in peptide backbone fragmentation into $\mathrm{c}$ - and $\mathrm{z} \bullet$-type ions. There fore this fragmentation is more useful for the analysis of posttranslational modification (PTM) such as phosphorylation (Syka et al. 2004) and glycosylation (Hogan et al. 2005). The feature makes this technique, together with ECD, a very attractive tool for the localization of the PTM attachment.

\section{Sample preparation and characterization}

The methods to study glycoproteins, glycopeptides or glycans in MS-based analyzes vary according to the specific research question. In many cases, these methods have been developed with the aim to selectively obtain the N-glycoproteome of a particular sample by MS analysis of the corresponding (deglycosylated) tryptic peptides to identify the underlying proteins. In these types of studies, N-glycosylation sites in tryptic glycopeptides usually are identified by conventional LC-MS/MS or MALDI-MS/MS analysis based on the conversion of Asn to Asp upon treatment with N-glycanase (PNGase), or on the localisation of the remaining GlcNAc-Asn tag upon treatment with endo-Nacetylglucosaminidases.

For the isolation of glycoproteins or glycopeptides by affinity chromatography various lectins have been used so far. Lectin chromatography using concanavalin A (Con A) has been reported for the enrichment of N-glycoproteins from diverse sources (Nasia et al. 2009). Enrichment techniques applied in combination with advanced MS/MS methods for the direct analysis of intact glycopeptides to obtain sequence information of both the glycan and the peptide moiety have been less commonly used. Now approaches using fragmentation techniques in glycopeptide and glycan analyses such as ESI, MALDI and LC/MS/MS-Q-Trap, are very popular to provide information on the peptide and glycan sequences, as well as on the attachment site.

\subsection{Characterisation of glycoproteins and glycopeptides}

Several methods and techniques have been applied to analyse the oligosaccharide structure of glycoproteins and glycopeptides. Applying both CID and ETD fragmentation techniques sequentially to protonated glycopeptides provides information on the glycan structure (CID) as well as the provide information on the peptide sequence and the glycan attachment site (ETD). The combination of these complementary data sets allows the detailed structural 
characterization of glycopeptides species characterization of glycopeptides is performed with different instrumental configurations, such as:

- $\quad$ MALDI-MS/MS

- $\quad$ Liquid chromatography systems compatible with on-line MS of glycopeptides

- $\quad$ ESI-MS/MS

- Capillary electrophoresis with on-line MS

\subsubsection{MALDI-MS and MS/MS analyses of glycopeptides}

MALDI-MS/MS of glycopeptides has been performed using the following instrumental configurations:

- $\quad$ MALDI-TOF with post source decay (PSD),

- MALDI-TOF/TOF,

- MALDI-quadrupole-TOF, and

- $\quad$ MALDI-IT/TOF MS.

MALDI-TOF/TOF MS of glycopeptides in protonated form has been established using 2,5dihydroxybenzoic acid (DHB) as a matrix (Uematsu et al. 2005; Wuhrer et al. 2004); the observed fragments result in the MS spectrum. Three different groups of fragment ion signals in MS are observed which provide information on both the peptide and glycan moiety of the glycopeptides. MALDI-TOF/TOF-MS of N-glycopeptides results in all the fragment ions retaining the peptide moiety, as well as in a set of cleavages at or near the innermost $\mathrm{N}$-acetylglucosamine residue. The signals [Mpep+H]+ and [Mpep+H-17]+ usually arising from the cleavage of the side-chain amide bond of the glycosylated asparagine are observed. Fragmentation characteristics are very similar to those observed with MALDIquadrupole /TOF-MS (Krokhin et al. 2005; Bykova et al. 2006) and MALDI-IT/TOF-MS (Demelbauer et al. 2004; Takemori et al. 2006).

\subsubsection{MALDI-MS and MS/MS analyses of glycosylation sites and determination of the occupancy at a particular site}

Determination of which sites in the glycoprotein are glycosylated and determination of the extent of occupation at each site are generally accomplished by performing trypsinolysis or other degradative reactions, generating a peptide/glycopeptide mixture. Glycopeptides can usually be selectively detected in such mixtures by precursor ion scanning, followed by MS/MS analysis of detected glycopeptides. This approach, however, is only straight forward for proteins with known amino acid sequence. This restriction, which originates from the dominance of the sugar fragments, can be overcome by performing MS/MS or MS3 on the $\mathrm{Y}_{1}$ ion (peptide + GlcNAc) generated via in-source fragmentation or MS/MS, respectively (Sandra et al. 2007).

Since the protein sequence of one subunit of Rapana venosa hemocyanin ( $\left.\mathrm{RvH}_{1}\right)$ is currently unknown, this approach was not applicable. Therefore, de novo MS sequencing was performed on the glycopeptides, obtained after tryptic digestion of RvH1 (Sandra et al. 2007). The glyco-moiety was removed from the glycopeptide because the sugar fragments often dominate the peptide fragments due to glycosidic bonds being more labile than peptide bonds. This is a phenomenon typically observed when using CID or PSD as fragmentation techniques. To solve this problem electron capture dissociation or electron transfer dissociation were applied. A method of labelling the N-glycosylation sites was used by performing a PNGase F digestion in a buffer containing $50 \% \mathrm{H}_{2}{ }^{18} \mathrm{O}$ ( Sandra et al. 2004a).

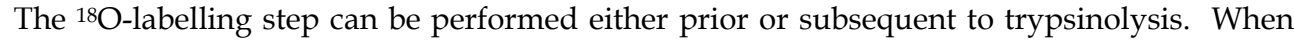


choosing this approach, it is important to remove the remaining $\mathrm{H}_{2}{ }^{18} \mathrm{O}$ to prevent unspecific incorporation of the label into all tryptic peptides. Also, trypsin needs to be removed from the hydrolysate. Since $\mathrm{H}_{2}{ }^{18} \mathrm{O}$ can easily be removed by membrane filtration, labelling the protein prior to the tryptic digestion was preferred. The complexity of the tryptic peptide mixture is reflected in the nano-LC-UV chromatogram. By way of example the MALDI-TOF spectrum corresponding to fraction 54, and an expanded view of the region containing the ${ }^{18} \mathrm{O}$-labelling peptide ions at 2406.3296, are presented in Fig. 5. Sequence information can be obtained by performing higher-order MS. The peptides containing the glycosylation sites were detected via the 2 Da spacing between the unlabelled and labelled ions using MS (Fig.5).

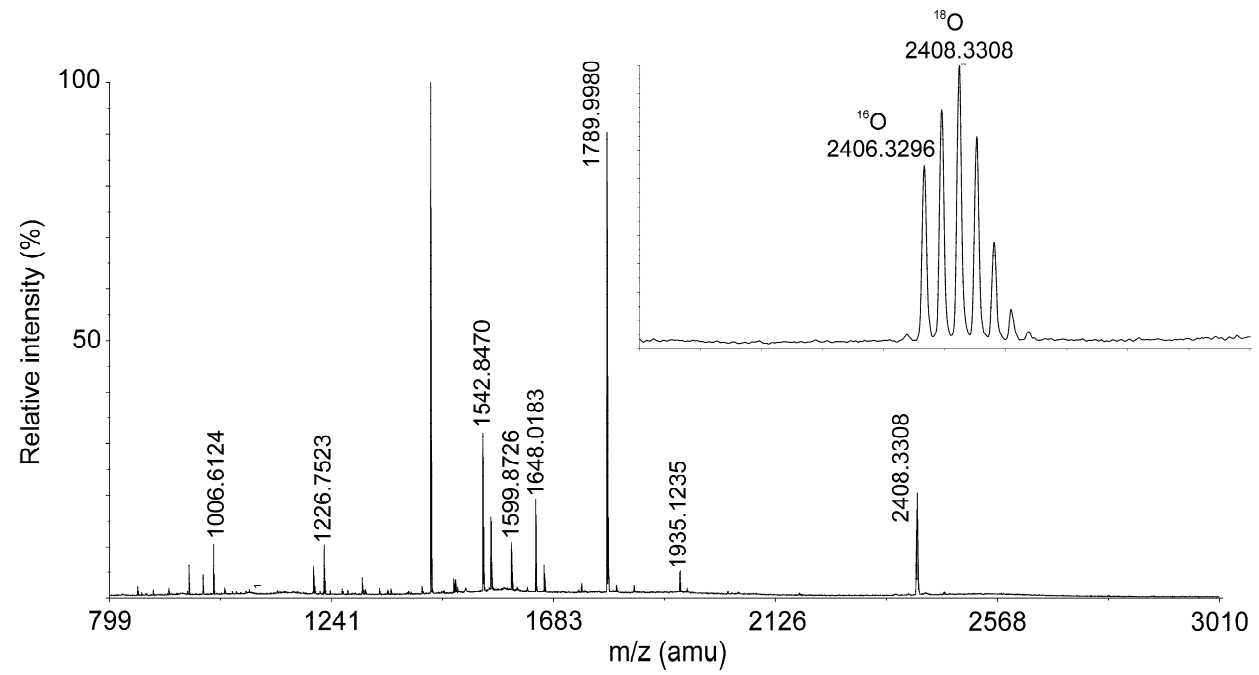

Fig. 5. The nano-LC-MALDI-TOF spectra corresponding to fraction 54 (b) and an expanded view of the regions containing the ${ }^{18} \mathrm{O}$-labelling peptide ions at $\mathrm{m} / \mathrm{z} 2406.3296$ (inset).

Using this approach, 6 glycopeptides were identified from the enormous complexity of the $\mathrm{RvH}_{1}$ tryptic digest. Nano-LC was used as a preceding separation step, and fractions were directly collected onto a MALDI-target.

\subsubsection{Characterisation of glycopeptides using MALDI-MS/MS and Q-Trap MS/MS analyses}

The structure Man5GlcNAc2 of the glycan with mass of $1257.4 \mathrm{Da}$ is represented with a specific fragmentation nomenclature in Q-Trap MS/MS spectrum. The MS/MS spectrum of the underivatised singly charged sodium-adduct is shown in Figure 6 . The most dominant ions are $\mathrm{Y}$ and $\mathrm{B}$ that arise from glycosidic cleavages. $\mathrm{C}$ and $\mathrm{Z}$ ions are also observed. They can be differentiated from the $\mathrm{Y}$ and $\mathrm{B}$ ions without derivatisation, because of the asymmetrical nature of the molecule. At this stage it is impossible to demonstrate the existence of a branched structure. Many interesting cross-ring cleavage ions are also present as $0,2 \mathrm{~A} 5,2,4 \mathrm{~A}_{4}, 0,3 \mathrm{~A} 3$, and $3,5 \mathrm{~A} 3$ ions rendue. They are very informative because they indicate a linkage of a trihexose at carbon 6 of a hexose. When the structure is not methylated, minor information can be extracted on the branching from the cross-ring cleavages. 


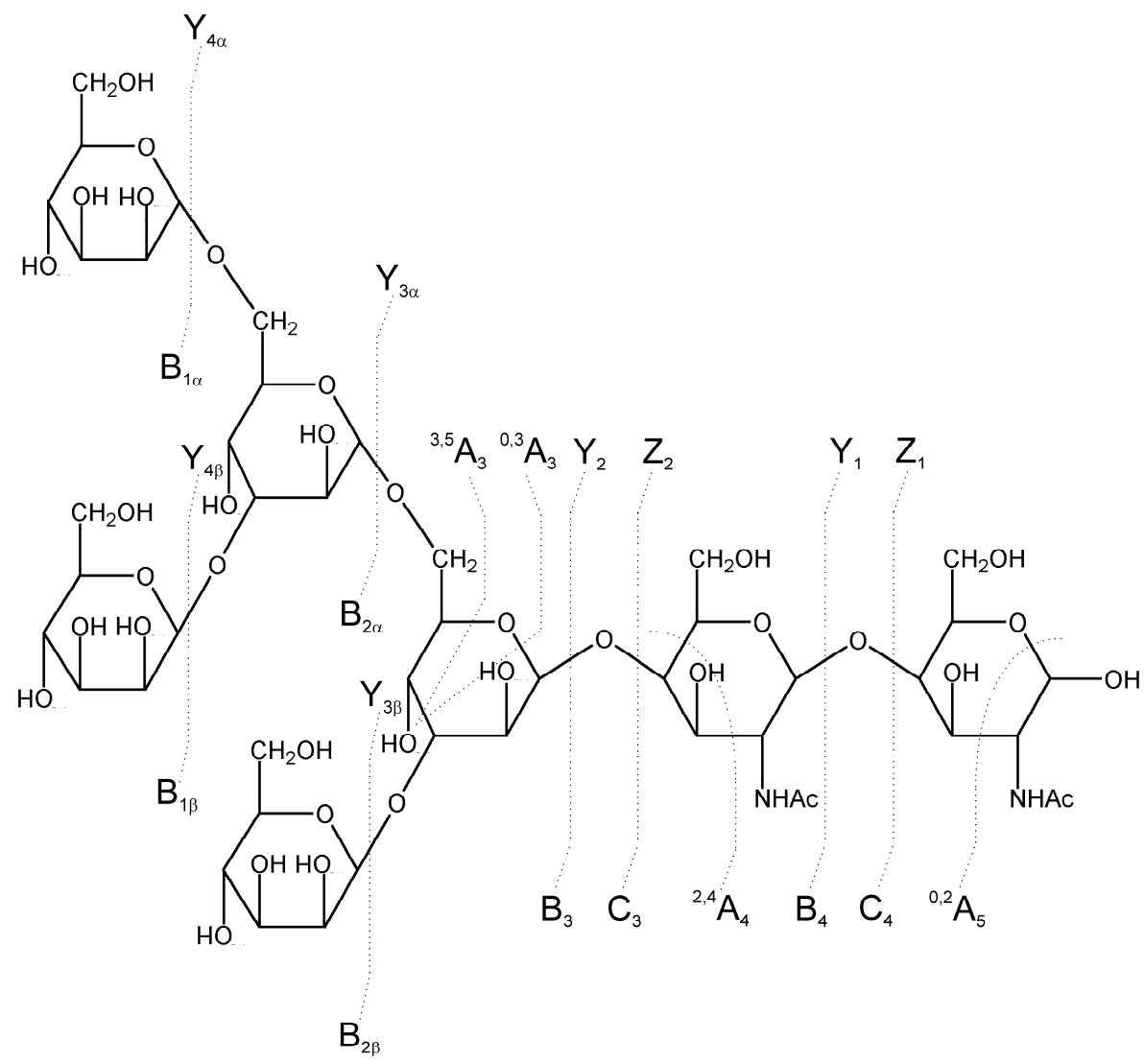

Fig. 6. Structure of the RNase B. Man ${ }_{5} \mathrm{GlcNAc2}$ N-glycan and fragmentation nomenclature.

MALDI-MS/MS and Q-Trap MS/MS have been performed to analyse the carbohydrate structure in the polypeptide chain of $\mathrm{Cu} / \mathrm{Zn}-\mathrm{SOD}$ from K. marxianus NBIMCC 1984 yeast (Dolashka-Angelova et al. 2010). The obtained fractions after treatment of the protein with trypsin were separated by HPLC and their amino acid sequences were determined by MALDI-TOF-TOF. One putative linkage site was observed in the sequence [EVWN(I/L)TGNSPNA(I/L)R] of the peptide with a mass of $1773.51 \mathrm{Da}$. The orcinol/ $\mathrm{H}_{2} \mathrm{SO}_{4}$ test was effectively positive, confirming that one glycopeptide is present in a fraction eluted at 19 min by HPLC. Structure of this glycopeptide was analysed by MALDI-MS/MS and QTrap MS/MS.

The amino acid sequence of the peptide chain EVWN(I/L)TGNSPNA(I/L)R was determined by MALDI-MS/MS, based on the singly-charged ions (Fig. 7). The difference between two single ions at m/z 1571.01 and m/z 1773.51 is corresponding to one GlcNAc connected to the peptide, which also demonstrates that the peptide of $1773.51 \mathrm{Da}$ is glycosylated. The on at 1359.23 is the same peptide as y11 [at m/z 1156.74, N(I/L)TGNSPNA(I/L)R], with one GlcNAc being connected to linkage site Asp-Ile/LeuThr. Evidently the linkage site (-Asn-Leu/Ile-Thr-) at position 33-35 is the glycosylated one. This linkage site is conserved in several SODs. 


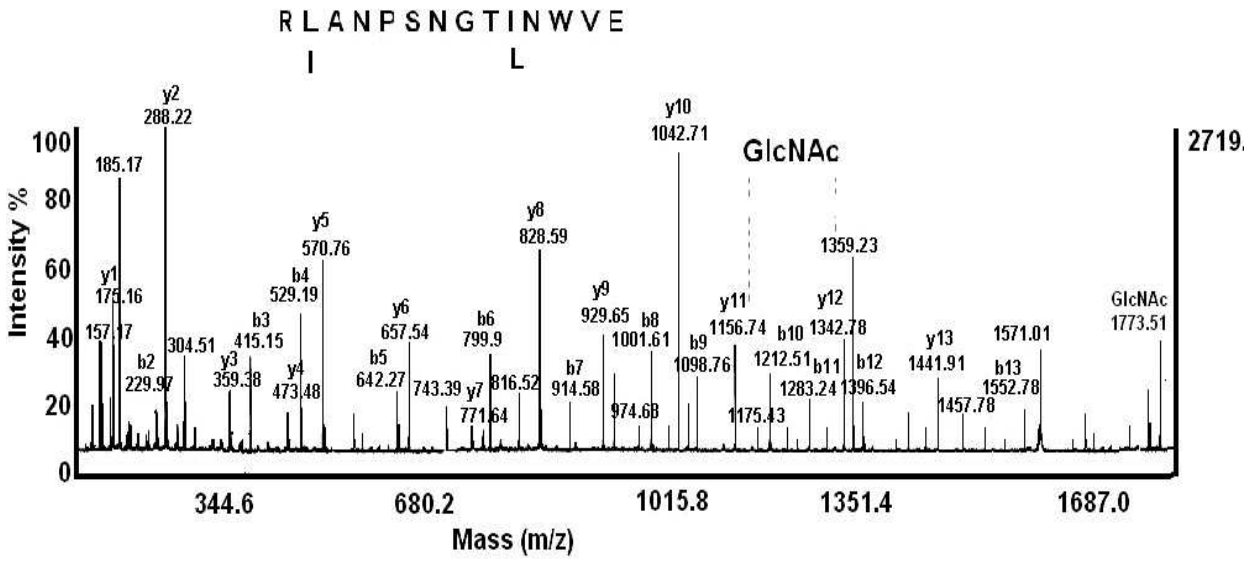

Fig. 7. MALDI-TOF-MS spectra of the N-glycan isolated from $\mathrm{Cu} / \mathrm{Zn}-\mathrm{SOD}$ from $\mathrm{K}$. marxianus NBIMCC 1984. $1 \mu \mathrm{l}$ of a 1:1 sugar-matrix mixture was applied onto the MALDI target. A matrix DHB $(10 \mathrm{mg} / \mathrm{ml}$ dihydroxybenzoic acid solution in $50 \% \mathrm{AcN})$ was used.

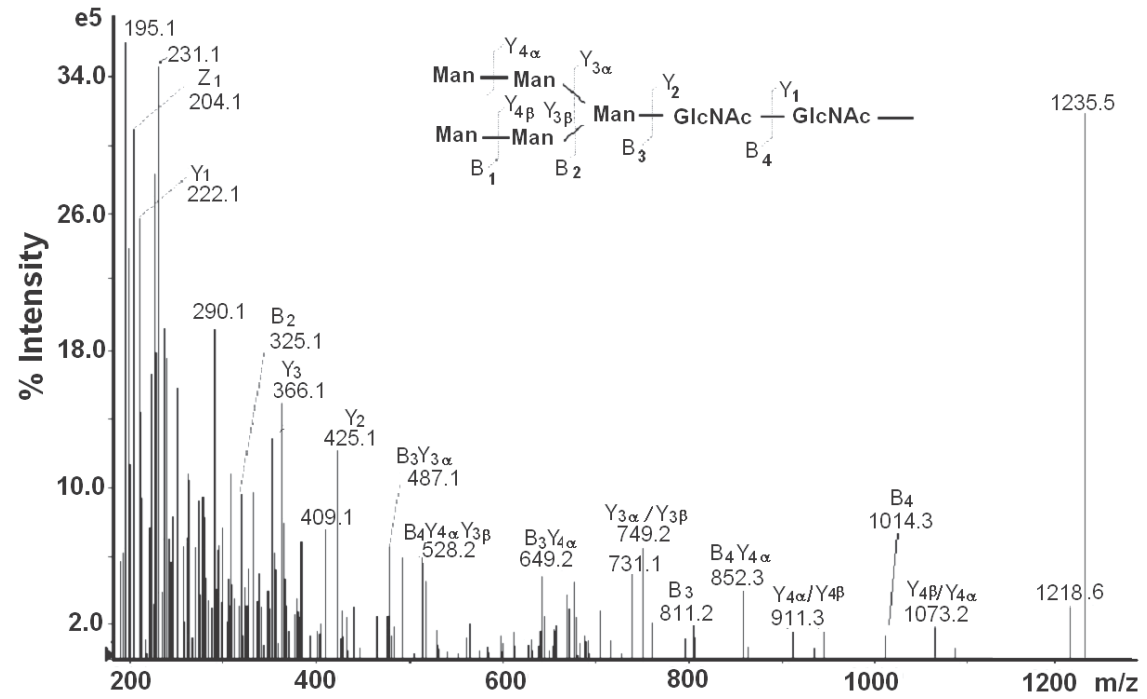

Fig. 8. MS/MS spectra on a Q-Trap mass spectrometer and structure with fragmentation nomenclature of the single charged $[\mathrm{M}+\mathrm{Na}]^{+}$of the glycan at $\mathrm{m} / \mathrm{z} 1235.52$, isolated from $\mathrm{Cu} / \mathrm{Zn}-\mathrm{SOD}$ from K.marxianus NBIMCC 1984.

After treatment of the peptide with PNGase F a single peak at $1257.3[\mathrm{M}+\mathrm{Na}]^{+}$was detected which suggests a uniform oligosaccharide chain. The structure of this carbohydrate chain was determined by Q-Trap MS/MS of the singly-charged ion with a mass of $1235.52 \mathrm{Da}$ $(\mathrm{M}+\mathrm{H})^{+}$as shown in Figure 8. The sequence can easily be read when considering the $\mathrm{Y}$ ions and the combination of $B$ and $Y$ ions $(\mathrm{m} / \mathrm{z} 222.1,325.1,425.1,811.2,1014.3)$. The structure, 
given as inset in the figure is a classical high mannose type of sugar (GlcNAc2, Man5), with a calculated mass of 1234.4 Da.

\subsubsection{Electrospray ionization-mass spectrometry (ESI-MS) of glycopeptides}

Electrospray is a soft ionization technique and can be performed on solid or liquid samples. Therefore, ESI is typically used to determine the molecular weights of proteins, peptides, and other biological macromolecules. Soft ionization is a useful technique when considering biological molecules of large molecular mass, as it turns the macromolecule being ionized into small fragments.

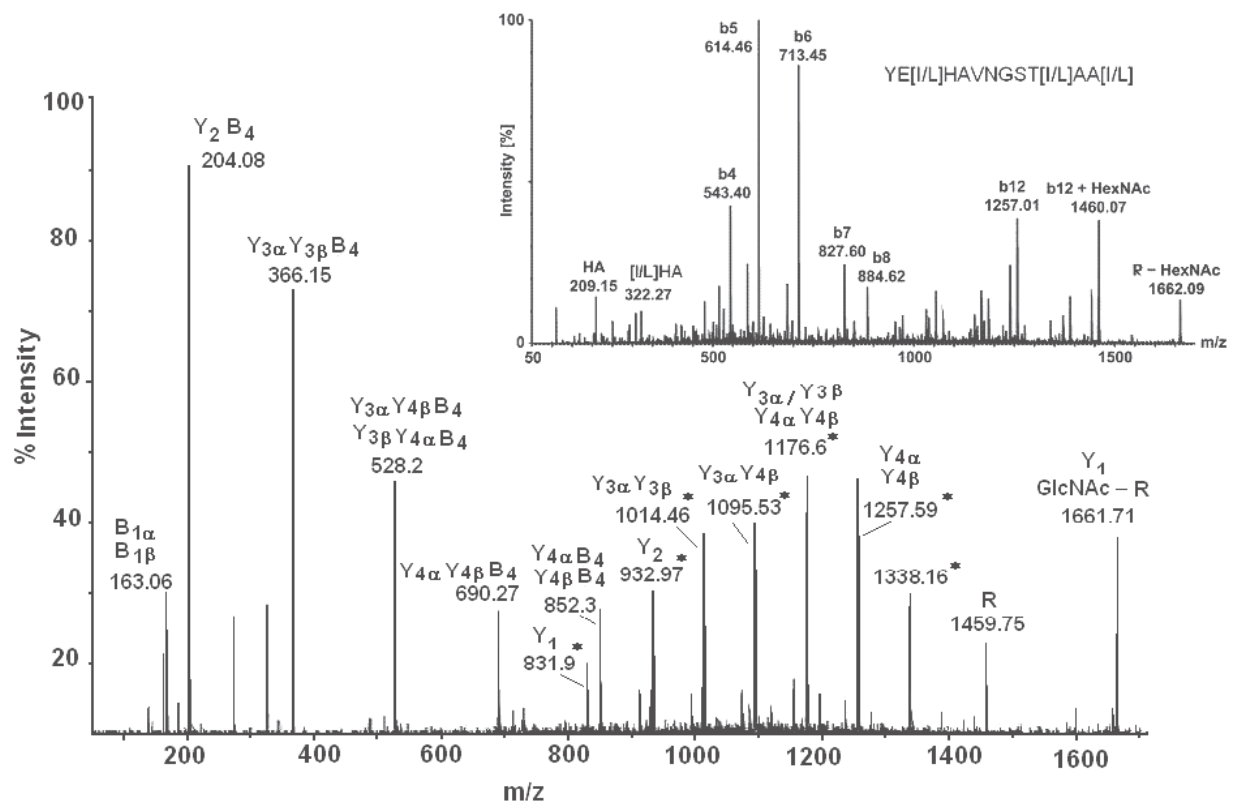

Fig. 9. Fragment spectra of the glycopeptide G1 with determined m/z $1338.16[\mathrm{M}+2 \mathrm{H}]_{2+}$. A) MS/MS analysis of the sugar moiety using a collision energy of $37 \mathrm{eV}$. Annotation of sugar fragments. The insert shows the complete carbohydrate structure and the cleavage points leading to the respective fragments. * - corresponds to the doubly charged ions B) PseudoMS/MS/MS experiment (in-source and collision-induced fragmentation) of the peptide moiety (YEXHAVN*GSTXAAX) still carrying one HexNAc (m/z 1662.09, [M - H]+), using a cone voltage of $95 \mathrm{~V}$ and a collision energy of $80 \mathrm{eV}$. R-corresponds to the peptide.

ESI and collision-induced dissociation (CID) on a triple-quadrupole mass spectrometer have already established several of the key features of CID of glycopeptides. ESI-MS was applied to analyse the glycopeptides obtained after treatment of Rapana hemocyanin with trypsin and being separated by HPLC (Beck et al. 2007; Sandra et al. 2007).

Six glycopeptides were characterized in detail by analyzing the corresponding HPLC fraction by ESI-MS/MS. The MS/MS spectra of one peptide appearing as a doubly protonated molecule of $\mathrm{m} / \mathrm{z} 1338.16[\mathrm{M}+2 \mathrm{H}]^{2+}$ in the MS spectrum itself (not shown) are displayed in Figure 9. 
The MS/MS spectrum of the fragment ion at $\mathrm{m} / \mathrm{z} 1661.71$, corresponding to the peptide (designated R-, m/z 1459.75), which is N-glycosylated, with a single residual GlcNAc residue, is shon on Figure 9. The spectrum is further dominated by glycan fragments which correspond to a classical mannose type of oligosaccharide, consisting of two N-acetylhexosamines (HexNAc) monomers as well as five hexose (Hex) residues. In a pseudo-MS3 experiment, the sugar side chain was removed by in-source fragmentation and the peptide with one remaining HexNAc residue was further fragmented in the hexapole collision cell. This allowed the sequence analysis of the peptide and the determination of the site to which the sugar chain was attached (Fig. 9, insert).

The amino acid sequence of the peptide was revealed to be YEXHAVN*GSTXAAX. The glycosylation site $\mathrm{N}^{*}$ was identified to be part of the typical N-glycosylation motif $\mathrm{N}$-aa-S/T, where aa can be any amino acid except proline. $X$ represents a leucine or isoleucine residue which could not be distinguished by the applied MS methods.

\subsubsection{Characterisation of glycopeptides using a Q-Trap LC/MS/MS system}

As was described in 4.1.2 and 4.1.3, MS analysis of glycopeptides may be performed after extensive purification, using HPLC fractions analyzed by flow injection analysis on a Q-TOF or ESI-mass spectrometer. In practice, characterisation of glycopeptides is very difficult, because they are often analyzed from complex peptide/glycopeptide mixtures. When such samples are subjected to LC-ESI-MS/MS analysis with collision-induced fragmentation, data evaluation methods which highlight the relevant glycopeptide MS data within the complex overall data set are required. Strategies applied to achieve this goal comprise the generation of diagnostic fragment ions in the MS-mode (without precursor selection) and/or MS/MS-mode (with precursor selection).

The Q-Trap system with its capabilities to perform typical triple quadrupole scans was additionally used and several glycopeptides from $\mathrm{RvH} 1$ were identified and characterized (Sandra et al. 2007). Glycopeptides, selectively detected in a proteolytic mixture by the appearance of collisionan induced marker oxonium ions, such as $\mathrm{m} / \mathrm{z} 163\left(\mathrm{Hex}^{+}\right), 204$ $\left(\mathrm{HexNAc}^{+}\right)$or $366(\mathrm{HexHexNAc})^{+}$, , were sequenced. The insert of Figure 9A shows the LC/MS/MS total ion current (TIC) chromatogram of the precursor ion scan (monitoring $\mathrm{m} / \mathrm{z} 204$ ) of the HPLC fraction at time $31.24 \mathrm{~min}$.

The Enhanced Resolution scan (not shown) showed that the glycopeptide with mass 2511.91 eluting at this moment was triply charged at $\mathrm{m} / \mathrm{z} 837.97[\mathrm{M}+3 \mathrm{H}] 3^{+}$. The precursor ion scan at time $31.24 \mathrm{~min}$ is presented in Figure 10 (insert). The MS/MS spectrum is dominated by glycan fragmentation series of $\mathrm{Y}$ - and B-ions, according to the Domon/Costello nomenclature.

However, peptide fragmentation (Roepstorff/Biemann cleavages) became more dominant when the collision energy was increased, allowing to deduce the peptide sequence MGQYGD(I/L)STNNTR from the series of $y$ - and b-ions (Fig. 10). The ion b13 (m/z 1439.6) or $y 13(\mathrm{~m} / \mathrm{z} 1457.5)$ correspond to the peptide which contains two potential linkage sites $\mathrm{D}(\mathrm{L} / \mathrm{I}) \mathrm{S}-$ and -NNT-.

Normally, D(L/I)S is not expected to be a linkage site, but, in the unlikely event that deglycosylation of a glycan linked asparagine had occurred during sample preparation, we thoroughly investigated this option. The ion y7 at $\mathrm{m} / \mathrm{z} 806.4$ corresponds to the C-terminal fragment of the peptide -(I/L)STNNTR, and the ion at m/z 1009.6 represents the same fragment still containing one GlcNAc moiety. This suggests that only the linkage site -NNTis glycosylated, most likely via a high mannose like structure. 


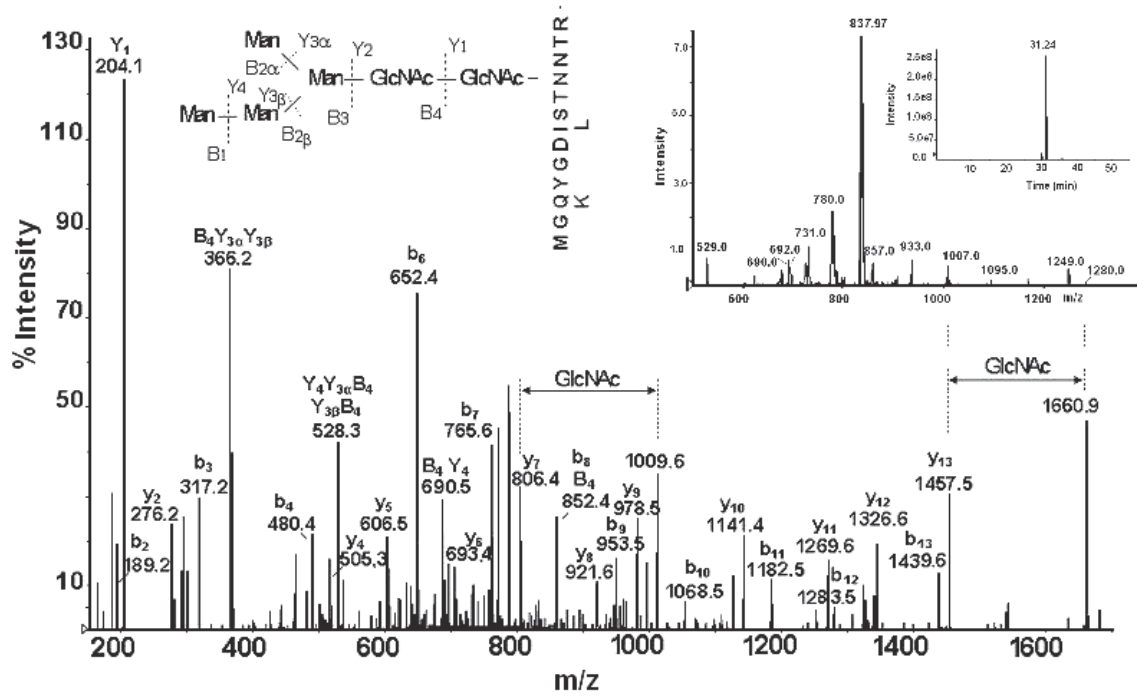

Fig. 10. Precursor ion scan (insert) at time 31,24 min of the chromatographic separation, and enhanced product ion (EPI) scan of the ion (B) at m/z 837.97.

The ion at m/z 1660.9 corresponds to the intact peptide, represented as ion y13 (m/z 1457.5), which is N-glycosylated with a single GlcNAc residue. The glycan structure of this peptide was determined following the typical ions as $\mathrm{Y}$ and $\mathrm{B}$ in MS/MS spectrum at $\mathrm{m} / \mathrm{z}$ 204.1 (GlcNAc), m/z 366.2 (HexGlcNAc), m/z 528.3 (Hex2GlcNAc), 690.5 (Hex3GlcNAc), and 852.4 (Hex4GlcNAc) (Fig. 10).

Combining all data, the carbohydrate structure of the glycan with mass $1054.0 \mathrm{Da}$ (Hex2Man3GlcNAc2) was suggested and the peptide sequence was determined MGQYGD(I/L)STNNTR.

\subsection{Structural characterization of glycans by MS/MS analyses}

While CID MS/MS techniques do routinely provide information on the glycan moieties of glycopeptides, they rarely reveal information on the peptide sequence and glycan attachment site(s). For a more detailed characterization of protein glycosylation, these techniques may be combined with other types of experiments. Glycopeptides may be treated with exoglycosidases revealing the nature and anomericity of terminal monosaccharide residues.

Alternatively, by treatment of glycopeptides with peptide-N-glycosidase F or A, N-glycans can be released and deglycosylated peptide moieties can be obtained. The peptides may then be subjected to mass spectrometric characterization.

Some glycans, obtained by us after digestion of proteins with PNGase F were identified by Q-Trap analysis. Analysis of the purified N-glycans by Q-Trap is a very sensitive and useful method and several glycans of the high mannose or complex types were identified following the sequence of B and $\mathrm{Y}$ ions in the MS/MS spectrum.

Two approaches were applied to analyse the isolated glycans after treatment of RvH1 with PNGase F (Dolashka-Angelova et al. 2010). The first approach included sequencing of the glycans by specific glycosidases and analysis of the fragments via MS before and after 
treatment with the enzymes. This approach provided only preliminary results about the structures of the glycans. Therefore, in the second approach, tandem mass spectrometry was applied. The glycan structure was derived from the MS/MS spectra, obtained on a hybrid quadrupole-linear ion trap mass spectrometer.

The same method and techniques were applied and the configurations of $15 \mathrm{~N}$-glycans released from Haliotis tuberculata hemocyanin (HtH1) after PNGase F-treatment were performed by Q-Trap tandem mass spectrometry (Velkova et al. 2011). Using both the MALDI-TOF-MS analysis after treatment of the glycans with the specific a1-6(>2,3,4) fucosidase and the Q-Trap-MS/MS analysis, core- structures containing Fuc(a1-6) GlcNAc, were detected.

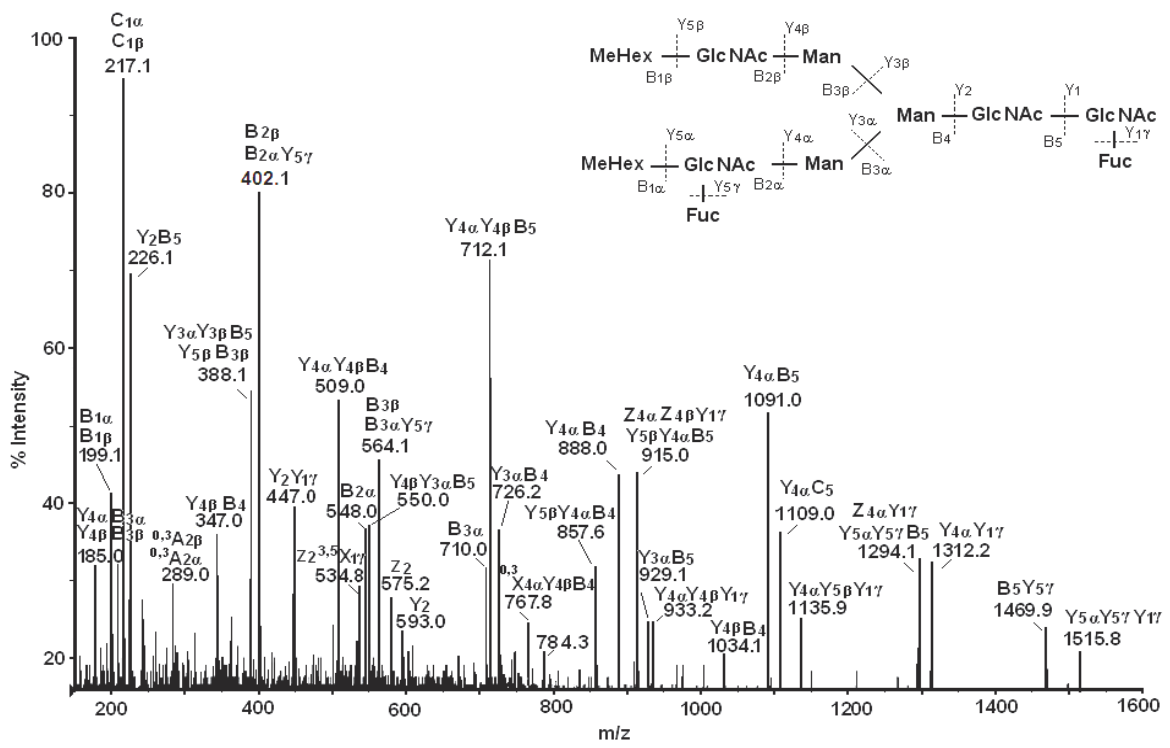

Fig. 11. MS/MS spectra and structures with fragmentation nomenclature of the double charged $[\mathrm{M}+2 \mathrm{Na}]^{2+}$ of the glycan at m/z 1002.8 isolated from $\mathrm{HtH} 1$.

In the MS/MS spectrum the most dominant $\mathrm{Y}$ and $\mathrm{B}$ ions provided information on the sequence and the branching, but the positions of the monosaccharides were confirmed by the $\mathrm{C}, \mathrm{Z}, \mathrm{X}$ and $\mathrm{A}$ ions. The interesting structure of one glycan was determined after sequencing the doubly-charged ion $\left([\mathrm{M}+2 \mathrm{Na}]^{2+}, \mathrm{m} / \mathrm{z} 1002.8\right.$, (Figure 11). As is shown in the spectrum, two deoxyhexose and two terminal methyl-Hex residues are linked to the internal GlcNAc of a molecule with the composition MeHex2HexMan3GlcNAc4Fuc2. Three ions, $\mathrm{Z}_{23,5} \mathrm{X}_{1_{\gamma}}$ at $\mathrm{m} / \mathrm{z} 534.8, \mathrm{Z}_{2}$ at $\mathrm{m} / \mathrm{z} 575.2$ and $\mathrm{Y}_{2}$ at $\mathrm{m} / \mathrm{z} 593.0$, demonstrate the presence of a core-linked Fuc(a1-6) residue. Confirmation of additional Fuc(a1-3) branching to GlcNAc are the ions $B_{2 \alpha}$ at $\mathrm{m} / \mathrm{z} 548.0$ and $\mathrm{B}_{3 \alpha}$ at $\mathrm{m} / \mathrm{z} 710.0$, as well as the ions $\mathrm{B}_{3 \beta}$ at $\mathrm{m} / \mathrm{z} 564.1$ and $\mathrm{B}_{5} \mathrm{Y}_{5 \gamma}$ at $\mathrm{m} / \mathrm{z}$ 1469.9, supporting the branching of two terminal MeHex residues. The observed cross-ring fragment ions $\mathrm{X}_{4 \beta} \mathrm{Y}_{4 \mathrm{a}} \mathrm{B}_{4}$, at $\mathrm{m} / \mathrm{z} 767.8$, as well as $0,3 \mathrm{~A}_{2 \mathrm{\alpha}}$, are additional evidence of the suggested structure Fuc(a1-3)GlcNAc. The ion $\mathrm{Y}_{4 \beta} \mathrm{B}_{4}$ at $\mathrm{m} / \mathrm{z} 1034.1$ corresponds to the composition Man3GlcNAcFucMeHex (carrying a (a1-3)-fucose terminal linkage at GlcNAc). 
Consequently, cross-ring fragment ion $\mathrm{X}_{4 \alpha} \mathrm{Y}_{4 \beta} \mathrm{B}_{4}$, at $\mathrm{m} / \mathrm{z} 767.8$, is resulting from the ion $\mathrm{Y}_{4 \beta} \mathrm{B}_{4}$ at $\mathrm{m} / \mathrm{z} 1034.1$ without $0,3 \mathrm{~A} 2 \mathrm{a}$ fragment, containing a MeHex moiety. The evidence of MeHex being linked to GlcNAc, as observed in most molluscan hemocyanins, is derived from the ions $\mathrm{C} 1 \alpha$ and $\mathrm{C} 1 \beta$ at $\mathrm{m} / \mathrm{z} 217.1$, ions $\mathrm{B}_{2 \beta}$ and $\mathrm{B}_{2 \alpha} \mathrm{Y}_{5 \gamma}$ at $\mathrm{m} / \mathrm{z}$ 402.1, as well as from the ions $\mathrm{B}_{3 \beta}$ and $\mathrm{B}_{3 \alpha} \mathrm{Y}_{5 y}$ at $\mathrm{m} / \mathrm{z}$ 564.1. Two alternatively interpretations of the signal at $\mathrm{m} / \mathrm{z} 1294$ as $\mathrm{Y}_{5 \alpha} \mathrm{Y}_{5 \gamma} \mathrm{B}_{5}$ and $\mathrm{Z}_{4 \alpha} \mathrm{Y}_{1 \gamma}$ confirm the positions of two fucoses.

Based on these data the structures of the isolated N-glycans from HtH1 were proposed (Velkova et al. 2011). It was found that most of the glycans have a common structural feature, one a1-6 linked fucose being attached to the trimannosyl core. Some of the structures have being partially modified by the methyl group, and in a few glycans a second or a third fucosyl residue in the Fuc(a1-3)GlcNAc motif were identified.

\subsection{Capillary electrophoresis and mass spectrometry}

\subsubsection{Characterization of glycopeptides by CE}

Capillary electrophoresis (CE) and capillary gel electrophoresis have been widely used for complex carbohydrate separation (Sandra et al. 2004b) because of enhanced separation efficiency and shorter analysis times. CE-based carbohydrate analysis can be applied easily to determine the molar ratio, and the degree of polymerisation of oligosaccharides, and to detect changes in the extent or nature of the oligosaccharide distribution (fingerprinting).

Using capillary electrophoresis, MALDI-MS and ESI-MS in combination with glycosidase digestion we studied the N-terminal functional unit (FU) $\mathrm{RvH}_{1}$-a of the structural subunit RvH1 (Dolashka-Angelova et al. 2004)(Fig. 12).

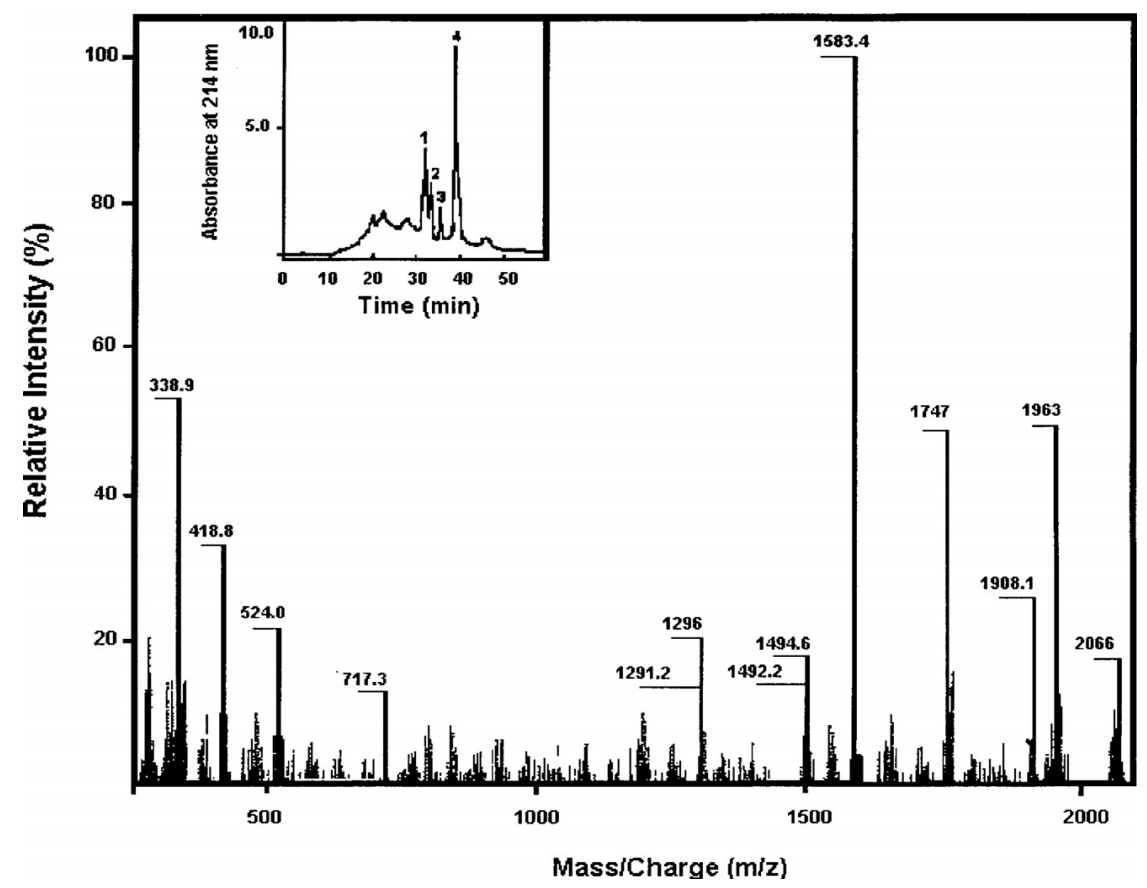

Fig. 12. ESI-MS and capillary electrophoresis of Glp1 following glycosidase digestion. 
Oligosaccharide fragments were released from the glycoprotein by Smith degradation and separated by means of a Superdex 300 column. Glycopeptide fragments, giving a positive reaction for the orcinol/ $\mathrm{H}_{2} \mathrm{SO}_{4}$ method, were separated by HPLC. The glycopeptide 1 with mass $2786 \mathrm{Da}$, was analyzed by MALDI-MS before and after treatment with PNGase-F. In the MALDI mass spectrum, acquired before PNGase-F treatment only one molecular ion at $2786 \mathrm{~m} / \mathrm{z}$ was detected, generated by the intact Glp1 sodium adduct ion [Glp1+Na] $]^{+}$In contrast, three signals were observed after PNGas-F treatment. The signal at $2786 \mathrm{~m} / \mathrm{z}$ is related to the intact Glp1, whereas the signal at $\mathrm{m} / \mathrm{z} 1609[\mathrm{M}+\mathrm{Na}]^{+}$is attributed to an oligosaccharide. The first signal $(1177 \mathrm{~m} / \mathrm{z})$ corresponds to the deglycosylated peptide. To determine the oligosaccharide sequence, ESI-MS and capillary electrophoresis of Glp1 were used, following glycosidase digestion (Fig. 12).

Different glycolytic enzymes were added to glycopeptide 1 : $\beta 1-2,3,4,6-$ GlcNAcase; $\alpha 1-2,3-$ mannosidase, $\alpha 1-2,3,6$ - mannosidase, $\beta 1-3,4,6$-galactosidase. The mass of this carbohydrate moiety (1586 Da, Table 1) would account for an oligosaccharidic chain containing ( $\left.\mathrm{SO}_{4}\right)$ MeGal GlcNAc4 Man3 being connected to the peptide.

\begin{tabular}{|c|c|c|c|}
\hline No & Enzymes & $\begin{array}{l}{[\mathrm{M}+\mathrm{H}]^{+}} \\
(\mathrm{m} / \mathrm{z})\end{array}$ & Structure of Glycopeptide 1 \\
\hline A & $\begin{array}{l}\alpha 1-2,3-\text { and } \alpha 1-2,3,6-\text { mannosidase } \\
\text { and } \beta 1-2,3,4,6-N-G l c N A c a s e\end{array}$ & 1747 & $\leftarrow \operatorname{Man}(\beta 1-4)$ GlcNAc $(\beta 1-4)$ GlcNAc $\neg \mathrm{P}$ \\
\hline B & $\begin{array}{l}\alpha 1-2,3-\text { mannosidase and } \\
\beta 1-2,3,4,6-N-G l c N A c a s e\end{array}$ & 1908 & $\begin{array}{l}\operatorname{Man}(a 1-6) \\
\kappa \\
\leftarrow \operatorname{Man}(\beta 1-4) \operatorname{GlcNAc}(\beta 1-4) \operatorname{GlcNAc} \neg P\end{array}$ \\
\hline $\mathrm{C}$ & $\begin{array}{l}\alpha 1-2,3,6 \text {-mannosidase and } \\
\alpha 1-2,3 \text {-mannosidase }\end{array}$ & 1953 & $3 \mathrm{MeGlcNAc}(\beta 1-2) \leftarrow \operatorname{Man}(\beta 1-4) \operatorname{GlcNAc}(\beta 1-4) \mathrm{GlcNAc} \neg \mathrm{P}$ \\
\hline $\mathrm{D}$ & $\beta 1-2,3,4,6-\mathrm{N}-G l c N A c a s e$ & 1583 & $-\operatorname{GlcNAc}(\beta 1-4)$ GlcNAc $\neg P$ \\
\hline
\end{tabular}

Table 1. Proposed structures of the carbohydrate chains of Glp1. The carbohydrate chains were calculated on the basis of observed $[\mathrm{M}+\mathrm{H}]+$ signals in the ESI mass spectra from Fig.12. P represents the peptide with sequence FANATSIDGPNA (1177 Da).

Depending on the specificity of the individual enzymes, the different linkages were identified by recording the pattern of molecular weights resulting from the digestion with the pool of glycosidases. After a $24 \mathrm{~h}$ incubation at $37^{\circ} \mathrm{C}$, the sample was first analyzed by capillary electrophoresis. Four different peaks were detected, indicating that the treatment causes heterogeneity resulting from different cleavage sites (Fig. 12, insert). On the basis of these results and an amino acid sequence analysis it was concluded that the functional unit $\mathrm{RvH} 1$-a contains $7 \%$ of oligosaccharides, that the glycans are $\mathrm{N}$-glycosidically attached to Asn262 and Asn401, and that the structure is as follows:

Glp 1

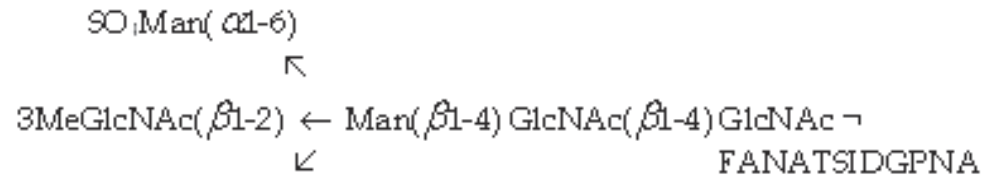

3eGal $(\beta 1-3) \mathrm{Gl} N \mathrm{NAd}(\beta 1-2) \operatorname{Man}(\alpha 1-3)$ 
Using capillary electrophoresis, in combination with MALDI-MS, ESI-MS and Q-TrapMS/MS (Fig. 13), the carbohydrate structure of several glycoproteins have been identified (Sandra et al. 2004 b; 2007).

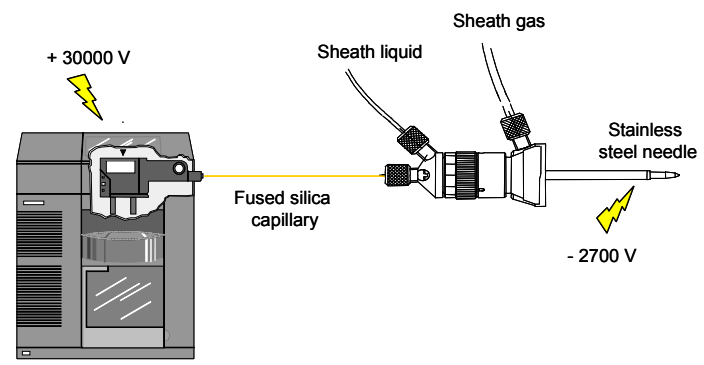

CE system
Electrospray ionisation interface

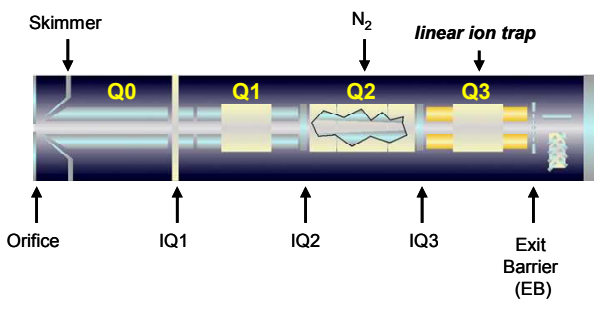

Q-Trap mass spectrometer

Fig. 13. Combination of CE, ESI and Q-Trap MS/MS system.

\subsubsection{Characterization of glycans by CE}

Labelling of the glycans has recently been proven to be of great value in the CE-MS/MS analysis of glycoproteins (Sandra et al. 2004 b).It permits high-resolution CE, allows the simultaneous detection of uncharged and charged glycans, and provides easily interpretable spectra. The latter label, representing a novel sugar tag, allows CE-MS detection in the positive ion mode and provides complementary information. The intact $\mathrm{RvH} 1$ was subjected to peptide-N-glycosidase F (PNGase F) digestion and the obtained glycans were labelled by 8-aminopyrene-1,3,6-trisulfonate (APTS) as well as by 3-aminopyrazole (3-AP). The Nglycans were analyzed by MALDI-TOF and CE-MS/MS.

MS/MS on APTS-derivatised sugars resulted in easily interpretable MS/MS spectra, since Y-fragments predominated. The CE-MS electropherogram of the APTS-labelled RvH1 Nglycans is presented in Figure 14 (insert) and, by way of an example, the on-line MS spectrum of the compound migrating at time $10.0 \mathrm{~min}$ is presented. This glycan is detected as a doubly and triply negatively charged ion and the composition corresponds to a fucosylated Man3GlcNAc2 core structure. From the MS/MS data obtained on the $[\mathrm{M}-2 \mathrm{H}]^{2-}$ ion at $\mathrm{m} / \mathrm{z} 748$, one can deduce that the fucose is attached to the proximal GlcNAc residue (Fig. 14).

The CE-MS(/MS) is a much more sensitive technique which allows identification of the presence of unusual structures. CE-MS/MS was performed to provide additional information of the oligosaccharide structure of RvH1. A new structure was suggested for the four times negatively charged ion at $\mathrm{m} / \mathrm{z} 555.7$ (Sandra et al. 2007). A sulphated oligosaccharide was observed before in $\mathrm{RvH}_{1}{ }^{10}$, and for the ion at $\mathrm{m} / \mathrm{z} 555.7$ the following sulphated structures can indeed be proposed: $\mathrm{SO}_{4} \mathrm{FucHex}_{4} \mathrm{Man}_{3} \mathrm{GlcNAc}_{2}$ and (SO4) ${ }_{2} \mathrm{FucHexHexNAc2Man3GlcNAc2.}$ 


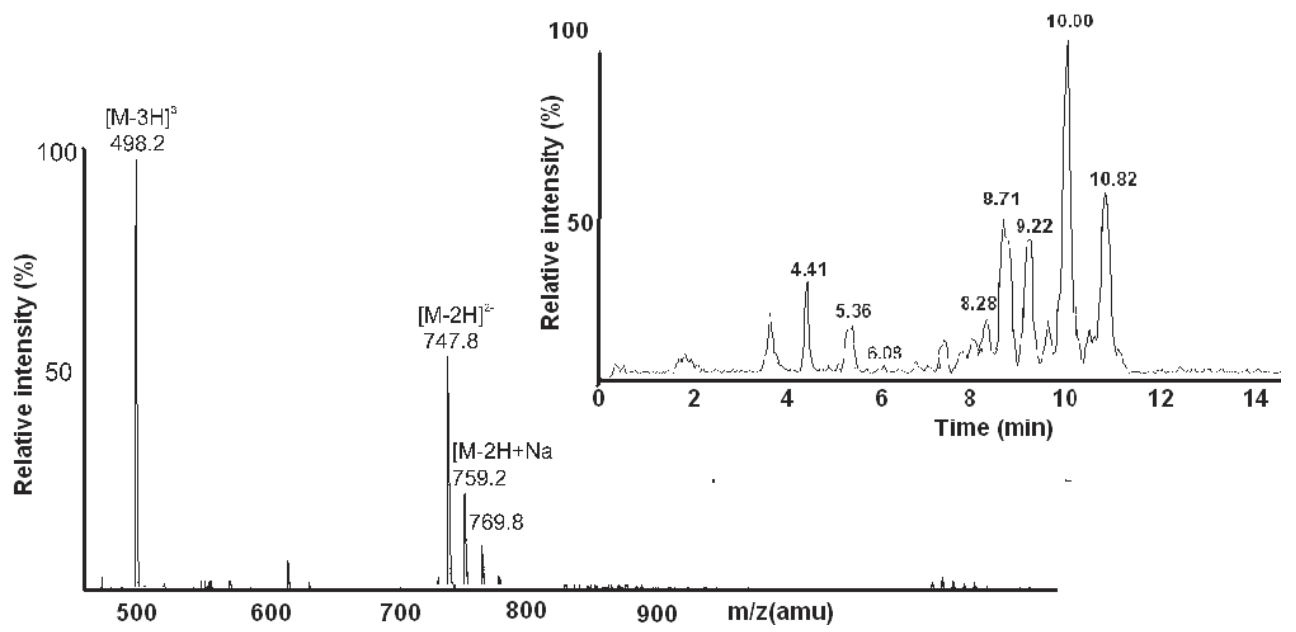

Fig. 14. On-line MS spectrum of the double charged ion at $\mathrm{m} / \mathrm{z} 747.8$ (insert). CE-MS base peak electropherogram of the APTS-labelled RvH1 N-glycans.

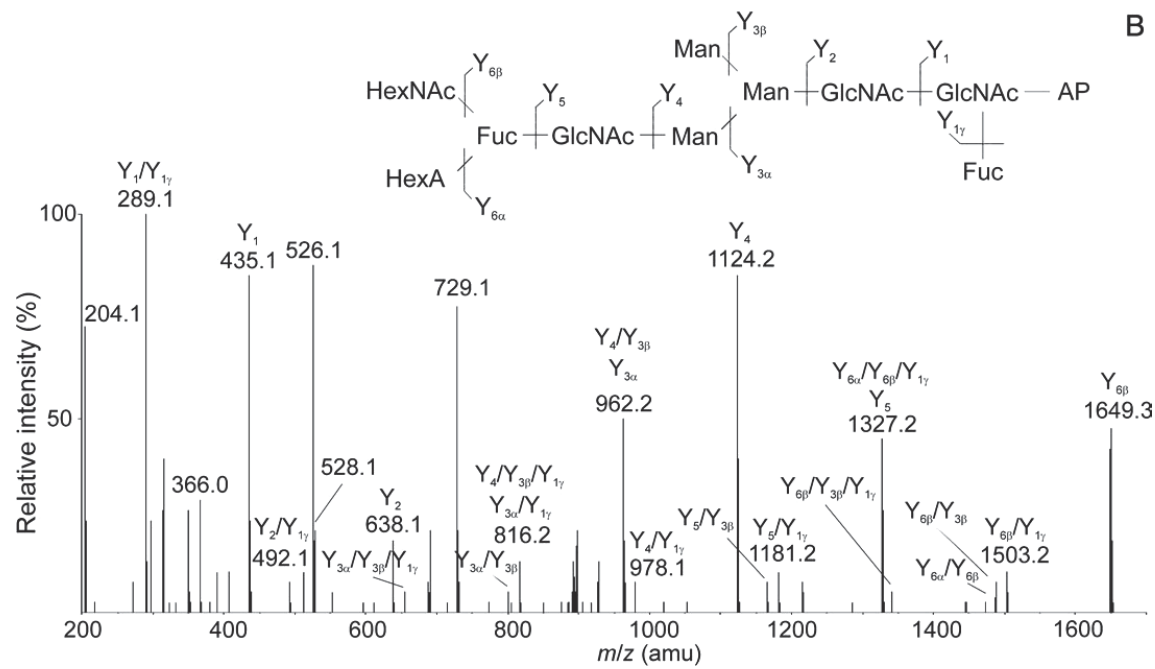

Fig. 15. CE-MS/MS electropherogram and tandem mass spectra of the compound at $\mathrm{m} / \mathrm{z}$ 555.7 (P, precursor ion).

In order to distinguish these two possibilities, the sample was reinjected for an on-line MS/MS experiment, keeping Q1 fixed to select the ion at m/z 555.7 (Figure 15). Apparently, CE could separate two isomeric compounds (eluted after 10.5 and $10.9 \mathrm{~min}$ ) with similar tandem mass spectra and, hence, the difference did not reside in the sequence. The spectra do not fit any of the sulfated glycans mentioned earlier.

Following MS/MS data, a structure with the HexAHexNAcFucGlcNAc oligosaccharide at both the $a-1,3$ and the $a-1,6$-arm could be suggested. 


\section{Conclusion}

Protein glycosylation plays an important role in a multitude of biological processes such as cell-cell recognition, growth, differentiation, and cell death. It has been shown that specific glycosylation changes are key in disease progression and can have a diagnostic value for a variety of disease types such as cancer and inflammation. The complexity of carbohydrate structures and their derivatives makes their study a real challenge.

Mass spectrometric (MS) techniques play a key role in glycoprotein and glycan analysis, study protein glycosylation at the glycopeptide level. Tandem mass spectrometry provides both the separation of glycopeptides and the ability to determine the glycan composition and site-specific glycosylation. Current informatics tools are designed for large, highthroughput mass-spectrometry datasets and can analyze numerous compounds, such as those in body fluids. The methods and strategies being developed are compatible with the problems of microheterogeneity commonly found, allowing characterization of even very complex minor components. Therefore, MS is becoming an increasingly important aspect in proteomics of eukaryotic cells.

\section{Acknowledgments}

This work was supported by a research grant 451 VS.016.009N of FWO (Belgium) and the Bulgarian Academy of Sciences; the Bulgarian National Science Fund TK01-496/2009, HTC01-187 (Ukraine), DFG-01/2008 (Germany) and CNR (Italy). The author is indebted to Prof. Josef Van Beemen (Gent, Belgium) for critically reading and correcting the text.

\section{References}

Ball, L.E.; Berkaw, M.N.; Buse, M.G. (2006). Identification of the Major Site of O-Linked $\beta-N$ Acetylglucosamine Modification in the C Terminus of Insulin Receptor Substrate-, Molecular and Cellular Proteomics, Vol. 5, (February 2006), pp.313-323, ISSN 15359484.

Bateman, K.P.;White, R.L.;Yaguchi, M.;Thibault, P. (1998). Characterization of proteinglycoforms by capillary-zone electrophoresis-nanoelectrospray mass spectrometry. Journal of Chromatography A, Vol.794, No.1/2,(January 1998),pp. 327344, ISSN 0021-9673.

Beck, A.; Hillen, N.; Dolashki, A.; Stevanovic, S.; Salvato, B.; Voelter, W.; DolashkaAngelova, P. (2007). Oligosaccharide structure of a functional unit RvH1-b of Rapana venosa hemocyanin using HPLC/electrospray ionization mass spectrometry. Biochimie, Vol.89, No.8, (August 2007), pp.938-949, ISSN 0300-9084.

Bykova, N.V.; Rampitsch, C.; Krokhin, O.; Standing, K.G.; Ens, W. (2006) Determination and Characterization of Site-Specific N-Glycosylation Using MALDI-Qq-TOF Tandem Mass Spectrometry: Case Study with a Plant Protease. Analytical Chemistry, Vol.78, No. 4, (January 2006), pp.1093-1103, ISSN 1520-6882.

Chalabi, S.; Panico, M.; Sutton-Smith, M.; Haslam, S.M.; Patankar, M.S.; Lattanzio, F.A.; Morris, H.R.; Clark, G.F.; Dell, A. (2006) Differential O-Glycosylation of a Conserved Domain Expressed in Murine and Human ZP3. Biochemistry, Vol.45, No.2, (2006), pp.637-647, ISSN 1520-4995. 
Dell, A.; Morris, H. R.(2001). Glycoprotein Structure Determination by Mass Spectrometry. Science, Vol.251. No. 5512, (March 2001), pp. 2351-2356, ISSN 1095-9203

Demelbauer, U.M.; Zehl, M.; Plematl, A.; Allmaier, G.; Rizzi, A. (2004) Determination of glycopeptide structures by multistage mass spectrometry with low-energy collision-induced dissociation: comparison of electrospray ionization quadrupole ion trap and matrix-assisted laser desorption/ionization quadrupole ion trap reflectron time-of-flight approaches. Rapid Communications in Mass Spectrometry, Vol.18, No. 14, (July 2004), pp. 1575-1582, ISSN 1097-0231.

Dolashka-Angelova, P.; Beck, A.; Dolashki, A.; Beltramini, M.; Stevanovic, S.; Salvato, B.;Hristova, R.; Velkova, L.; Voelter, W. (2004). Carbohydrate moieties of molluscan Rapana venosa hemocyanin. Micron, Vol. 35, No. 1-2, (January/February 2004), pp. 101-104, ISSN 0968-4328

Dolashka-Angelova, P.; Moshtanska, V; Kujumdzieva, A.; Atanasov, B.; Petrova, V.; Voelter, W.; Van Beeumen, J. (2010). Structure of glycosylated Cu/Zn-superoxide dismutase from kluyveromyces yeast NBIMCC 1984. Journal of Molecular Structure, Vol.980, No.1-3, (September 2010), pp.18-23, ISSN 0022-2860.

Domon, B.; Aebersold, R. Mass Spectrometry and Protein Analysis. Science, Vol. 312, No. 5771, (April 2006), pp. 212-217,ISSN 1095-9203

Froehlich, J.W.; Barboza, M.; Chu, C.; Lerno, L.A.; Clowers, B.H.; Zivkovic, A.M.; German, J.B. and Lebrill, C.B. (2011) Nano-LC-MS/MS of Glycopeptides Produced by Nonspecific Proteolysis Enables Rapid and Extensive Site-Specific Glycosylation Determination. Analytical Chemistry, Vol.83, No.14, (June 2011), pp.5541-5547, ISSN ISSN 1520-6882.

Gonzales de Peredo, A.; Klein, D.; Macek, B.; Hess, D.; Peter-Katalinic, J.; Hofsteenge, J. (2002). C-Mannosylation and -Fucosylation of hrombospondin Type 1 Repeats. Molecular and Cellular Proteomics, Vol.1, (2002), pp.11-18, ISSN 1535-9484.

Håkansson, K.; Chalmers, M.J.; Quinn, J.P.; McFarland, M.A.; Hendrickson, C.L.;Marshall, A.G. (2003). Combined electron capture and infrared multiphoton dissociation for multistage MS/MS in a Fourier transform ion cyclotron resonance mass spectrometer. Analytical Chemistry. Vol.75, No.13, (May 2003), pp. 3256-3262, ISSN $1520-6882$.

Håkansson, K.; Cooper, H.J.; Emmett, M.R.; Costello, C.E.; Marschall, A.G.; Nilsson, C.L. (2001). Electron capture dissociation and infrared multiphoton dissociation MS/MS of an N-glycosylated tryptic peptide to yield complementary sequence information. Analytical Chemistry, Vol. 73, No.18,(August 2001), pp.4530-4536, ISSN 1520-6882.

Harvey, D.J. (2006). Analysis of carbohydrates and glycoconjugates by matrixassisted laser desorption/ionization mass spectrometry: An update covering the period 19992000. Mass Spectrometry Reviews, Vol.25, No. 4, (July/August 2006), pp.595-662, ISSN 1098-2787.

Hogan, J.M.; Pitteri, S.J.; Chrisman, P.A.; McLuckey, S.A. (2005). Complementary Structural Information from a Tryptic $N$-Linked Glycopeptide via Electron Transfer Ion/Ion Reactions and Collision-Induced Dissociation. Journal of Proteome Research, Vol.4, 2, (April 2005), pp.628-632, ISSN 1535-3907.

Huddleston, M.J.; Bean, M.F.; Carr, S.A. (1993) Collisional fragmentation of glycopeptides by electrospray ionization LC/MS and LC/MS/MS: methods for selective 
detection of glycopeptides in protein digests. Analytical Chemistry, Vol. 65, No. 7, (April 1993), pp. 877-884, ISSN 1520-6882.

Krokhin, O.V.; Ens, W.; Standing, K.G. (2005) MALDI Q-TOF MS Combined with Off-line HPLC for Characterization of Protein Primary Structure and Post-Translational Modifications. Journal of Biomolecular Techniques, Vol. 16, No.4, (December 2005), pp.429-440, ISSN 1524-0215

Macek, B.; Hofsteenge, J.; Peter-Katalinic, J. (2001) Direct determination of glycosylation sites in O-fucosylated glycopeptides using nano-electrospray quadrupole time-offlight mass spectrometry. Rapid Communications in Mass Spectrometry, Vol. 15, No. 10, (May 2001), pp. 771-777, ISSN 1097-0231.

Medzihradszky, K.F.; Gillece-Castro, B.L.; Townsend, R.R.; Burlingame, A.L.; Hardy, M.R. (1996) Structural elucidation of $o$-linked glycopeptides by high energy collisioninduced dissociation. Journal of the American Society for Mass Spectrometry, Vol. 7, No. 4, (April 1996), pp. 319-328, ISSN 1044-0305.

Medzihradszky, K.F. (2005). Peptide sequence analysis. Methods Enzymology, Vol.402, (2005), pp. 209-244, ISSN 0076-6879.

Morelle, W.; Michalski, J.C. (2005). The Mass Spectrometric Analysis of Glycoproteins and Their Glycan Structures. Current Analytical Chemistry,Vol. 1, No.1, (January 2005), pp. 29-57, ISSN 1573-4110.

Nasia, A.; Picariellob, G.; Ferrantia, P. (2009). Proteomic approaches to study structure, functions and toxicity of legume seeds lectins. Perspectives for the assessment of food quality and safety. Journal of Proteomics, Vol. 72, No.3, (April 2009), pp. 527538, ISSN 1874-3919.

Patwa, T.; Li, Chen; Simeone D. M., Lubman, D. M. (2010). Clycoprotein analysis using protein microarrays and mass spectrometry. Mass Spectrometry Reviwes, Vol.29, No.5, (September/October 2010), pp.830-844, ISSN 1098-2787.

Sandra, K.; Dolashka-Angelova, P.; Deversee, B. and Beeumen, J.V. (2007). New insights in Rapana venosa hemocyanin N-glycosylation resulting from on-line mass spectrometric analyses. Glycobiology, Vol.17, No.2, (2007), pp. 141-156, ISSN 14602423.

Sandra, K.; Stals, I.; Sandra, P.; Claeyssens, M.; Beeumen, J.V and Devreese, B. (2004a). Combining gel and capillary electrophoresis, nano-LC and mass spectrometry for the elucidation of post-translational modifications of Trichoderma reesei cellobiohydrolase. Journal of Chromatography A, Vol. 1058, No.1-2, (November 2004), pp. 263-272, ISSN 0021-9673.

Sandra, K.; Van Beeumen, J.; Stals, I.; Sandra, P.; Claeyssens, M.; Devreese, B. (2004b). Characterization of cellobiohydrolase I N-glycans and differentiation of their phosphorylated isomers by capillary electrophoresis-Q-Trap mass spectrometry. Analytical Chemistry, Vol.76, No.19, (August 2004), pp.5878-5886, ISSN 1520-6882.

Syka, J.E.P.; Coon, J.J.; Schroeder, M.J.; Shabanowitz, J.; Hunt, D.F. (2004) Peptide and protein sequence analysis by electron transfer dissociation mass spectrometry. Proc. Natl. Acad. Sci. U.S.A., Vol. 101 (2004) 9528-9533.

Tadjiri, M.; Yoshida, S.; Wada, Y. (2005) Differential analysis of site-specific glycans on plasma and cellular fibronectins: application of a hydrophilic affinity method for glycopeptide enrichment.Glycobiology, Vol.15, No.12,(July 2005), pp. 1332-1340, ISSN 1460-2423. 
Takemori, N.; Komori, N.; Matsumoto, H. (2006). Highly sensitive multistage mass spectrometry enables small-scale analysis of protein glycosylation from twodimensional polyacrylamide gels. Electrophoresis, Vol. 27, No.7, (Aprl 2006), pp. 1394-1406, ISSN 1522-2683.

Uematsu, R.; Furukawa, J.; Nakagawa, H.; Shinohara, Y.; Deguchi, K.; Monde, K.; Nishimura, S. (2005) High Throughput Quantitative Glycomics and Glycoformfocused Proteomics of Murine Dermis and Epidermis. Molecular and Cellular Proteomics, Vol.4 (December 2005), pp.1977-1989, ISSN 1535-9484.

Velkova, L.; Dolashka, P.; Lieb, B.; Dolashki, A.; Voelter, W.; Beeumen, J. V. and Devreese, B. (2011). Glycan structures of the structural subunit (HtH1) of Haliotis tuberculata hemocyanin. Glycoconjugate Journal, Vol. 28, No. 6,( August 2011), pp. 385-395, ISSN 1573-4986.

Vosseller, K.; Trinidad, J.C.; Chalkley, R.J.; Specht, C.G.; Thalhammer, A.; Lynn, A.J.; Snedecor, J.H.; Guan, S.; Medzihradszky, K.F.; Maltby, D.A.; Schoepfer, R.; Burlingame, A.L. (2006) O-Linked N-Acetylglucosamine Proteomics of Postsynaptic Density Preparations Using Lectin Weak Affinity Chromatography and Mass Spectrometry. Molecular and Cellular Proteomics, Vol.5, (May 2006), pp.923-934, ISSN $1535-9484$.

Wada, Y. (2008) Mass Spectrometry of Glycopeptides. Experimental Glycoscience: Glycochemistry, Springer 2008, Part 1, Section III, EISBN: 978-4-431-77924-7.

Wuhrer, M.; Hokke, C.H.; Deelder, A.M. (2004) Glycopeptide analysis by matrix-assisted laser desorption/ionization tandem time-of-flight mass spectrometry reveals novel features of horseradish peroxidase glycosylation. Rapid Communcations in Mass Spectrometry, Vol.18, No. 15, (August 2004), pp.1741-1748, ISSN 1097-0231.

Zaia, J. (2004). Mass spectrometry of oligosaccharides. Mass Spectrometry Reviews, Vol.23, No.3, (May/June 2004), pp.161-227, ISSN 1098-2787. 


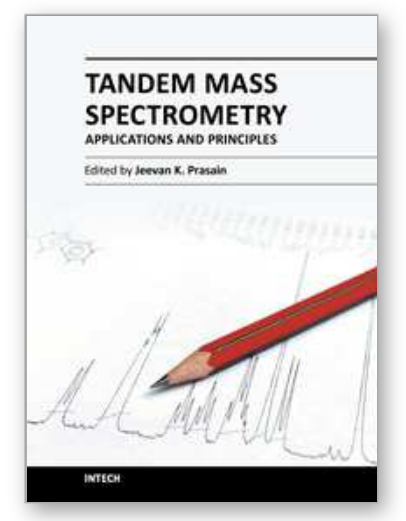

\author{
Tandem Mass Spectrometry - Applications and Principles \\ Edited by Dr Jeevan Prasain
}

ISBN 978-953-51-0141-3

Hard cover, 794 pages

Publisher InTech

Published online 29, February, 2012

Published in print edition February, 2012

Tandem Mass Spectrometry - Applications and Principles presents comprehensive coverage of theory, instrumentation and major applications of tandem mass spectrometry. The areas covered range from the analysis of drug metabolites, proteins and complex lipids to clinical diagnosis. This book serves multiple groups of audiences; professional (academic and industry), graduate students and general readers interested in the use of modern mass spectrometry in solving critical questions of chemical and biological sciences.

\title{
How to reference
}

In order to correctly reference this scholarly work, feel free to copy and paste the following:

Pavlina Dolashka (2012). Tandem Mass Spectrometry and Glycoproteins, Tandem Mass Spectrometry Applications and Principles, Dr Jeevan Prasain (Ed.), ISBN: 978-953-51-0141-3, InTech, Available from: http://www.intechopen.com/books/tandem-mass-spectrometry-applications-and-principles/tandem-massspectrometry-and-glycoproteomics

\section{INTECH}

open science | open minds

\author{
InTech Europe \\ University Campus STeP Ri \\ Slavka Krautzeka 83/A \\ 51000 Rijeka, Croatia \\ Phone: +385 (51) 770447 \\ Fax: +385 (51) 686166 \\ www.intechopen.com
}

\author{
InTech China \\ Unit 405, Office Block, Hotel Equatorial Shanghai \\ No.65, Yan An Road (West), Shanghai, 200040, China \\ 中国上海市延安西路65号上海国际贵都大饭店办公楼 405 单元 \\ Phone: +86-21-62489820 \\ Fax: $+86-21-62489821$
}


(C) 2012 The Author(s). Licensee IntechOpen. This is an open access article distributed under the terms of the Creative Commons Attribution 3.0 License, which permits unrestricted use, distribution, and reproduction in any medium, provided the original work is properly cited. 